Short report

\title{
Effectiveness of a mass media campaign to recruit young adults for testing of Chlamydia trachomatis by use of home obtained and mailed samples
}

\author{
Berit Andersen, Lars Østergaard, Jens K Møller, Frede Olesen
}

Objective: To evaluate the effectiveness of a structured information campaign aiming to recruit young adults for a Chlamydia trachomatis test by use of a non-invasive, home obtained and mailed sample.

Methods: All individuals aged 21-23 living in Aarhus county, Denmark (30 000 young adults) were offered a mailed home sampling test for $C$ trachomatis as part of a structured 14 week information campaign on chlamydia. The kit for home sampling could be requested by leaving a message on an answering machine or through a website on the internet.

Results: During the campaign 119 of 15000 women $(0.8 \%)$ and 64 of 15000 men $(0.4 \%)$ were tested. Prevalence of infection was $8.4 \%(10 / 119)$ and $7.8 \%(5 / 64)$ in females and males, respectively. Four infections in women $(4 / 10=40 \%)$ and three infections in men $(3 / 5=60 \%)$ were asymptomatic.

Conclusions: The mass media campaign had only a limited effect, and there is a need for more effective outreach programmes to recruit young asymptomatic individuals for $C$ trachomatis testing.

(Sex Transm Inf 2001;77:416-418)

Keywords: mass media; screening; Chlamydia trachomatis

\section{Introduction}

Urogenital Chlamydia trachomatis infection is widespread $^{1}$ and may cause female infertility and ectopic pregnancy. ${ }^{2}$ Diagnostic tests based on DNA amplification have made outreach sampling possible, ${ }^{3}$ and several studies have shown the feasibility of applying such test strategies in the field, ${ }^{4}$ in military settings, ${ }^{5}$ and in schools. ${ }^{67}$ However, strategies based on offering tests to individuals in particular settings do not provide equal access to health care for all. Therefore, there is a need for evaluation of the effectiveness of test strategies targeting the whole population.

The aim of this study was to assess the effectiveness of a mass media campaign to recruit young adults for $C$ trachomatis testing by use of home obtained mailed samples.

B Andersen

F Olesen

Department of Clinical Microbiology, Aarhus University Hospital, DK-8000 Aarhus C,

Denmark

J K Møller

Research Unit Q, Department of Infectious Diseases, Skejby Sygehus, Aarhus University Hospital, DK-8000 Aarhus C, Denmark L Østergaard

Correspondence to: Dr B Andersen duchand@dadlnet.dk

Accepted for publication 30 August 2001

\section{Material and methods \\ SUBJECTS}

Based on previous studies of prevalence in various age groups we chose the target population to be all individuals aged 21-23 who lived in Aarhus county, Denmark. This population comprised approximately 15000 men and 15000 women according to the central registration.

\section{INTERVENTION}

The study was carried out in the period 16 March 1998 to 19 June 1998. In this period an information campaign using mass media was performed. The aim was to recruit individuals for $C$ trachomatis testing by use of mailed home obtained samples.

\section{Content of campaign}

All the material used in the campaign contained information about the infection and its potential consequences and information on how to order a test package. The campaign consisted of the following: (1) a home page on the internet; (2) general information to the press with several articles in newspapers, radio interviews, as well as interviews in local and nationwide television; (3) posters and leaflets placed in education centres, halls of residence, sport clubs, libraries, physicians offices, and on advertising pillars; (4) posters on bicycle errand boys; (5) posters in buses; and (6) advertising on local radio channels. The total cost of the information campaign (excluded testing) was $£ 6000$ (75000 DKr).

\section{Ordering of test package}

Test packages for $C$ trachomatis testing could be requested from an answering machine or by email. Requests from individuals who did not live in Aarhus county were not processed. The test package included a first void urine sample tube (men) or a vaginal pipette ${ }^{3}$ (women), a written instruction on how to obtain the sample, and a prestamped, preaddressed envelope for returning the sample to the laboratory. Furthermore, information about the study and chlamydia infection in general was given.

\section{Submission of samples}

Samples were obtained at home by the individuals themselves and mailed directly to the laboratory as previously described. ${ }^{368}$ Participants were requested to state their personal identification number (mandatory for medical service in Denmark), whether they had any 
Table 1 Individuals ordering material for home sampling and submitting samples in the study

\begin{tabular}{|c|c|c|c|}
\hline & Women & Men & Total \\
\hline \multicolumn{4}{|l|}{ Individuals ordering material } \\
\hline \multicolumn{4}{|l|}{ Living outside the county* } \\
\hline through internet & 8 & 16 & 24 \\
\hline through answering machine & 1 & 2 & 3 \\
\hline \multicolumn{4}{|l|}{ Living in the county } \\
\hline on internet & 18 & 18 & 36 \\
\hline on answering phone & 178 & 128 & 306 \\
\hline \multicolumn{4}{|l|}{ Individuals submitting samples } \\
\hline total $\dagger$ & 147 & 86 & 233 \\
\hline from the target population & 119 & 64 & 183 \\
\hline in percentage of target population & $0.8 \%$ & $0.4 \%$ & $0.6 \%$ \\
\hline & $(119 / 15000)$ & $(64 / 15000)$ & $(183 / 30000)$ \\
\hline \multicolumn{4}{|l|}{ Prevalence of infection } \\
\hline in samples submitted by target population & $\begin{array}{l}8.4 \% \\
(10 / 119)\end{array}$ & $\begin{array}{l}7.8 \% \\
(5 / 64)\end{array}$ & $8.2 \%$ \\
\hline Infected without symptoms & $\begin{array}{l}40 \% \\
(4 / 10)\end{array}$ & $\begin{array}{l}60 \% \\
(3 / 5)\end{array}$ & \\
\hline
\end{tabular}

*The 27 individuals who did not live in Aarhus county did not receive material for home sampling (exclusion).

†Individuals not belonging to the target population (aged 21-23 years) were excluded.

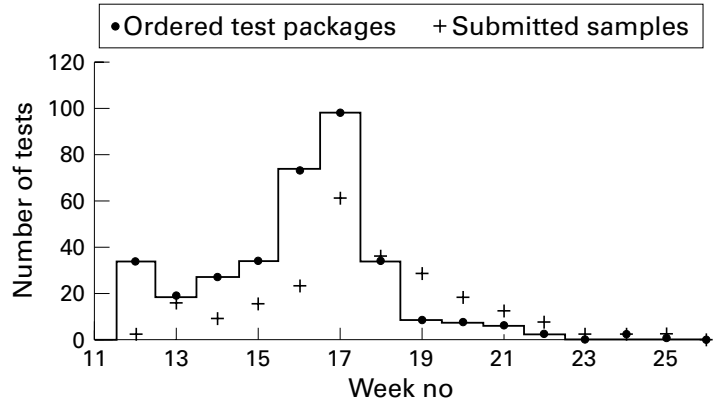

Content of campaign

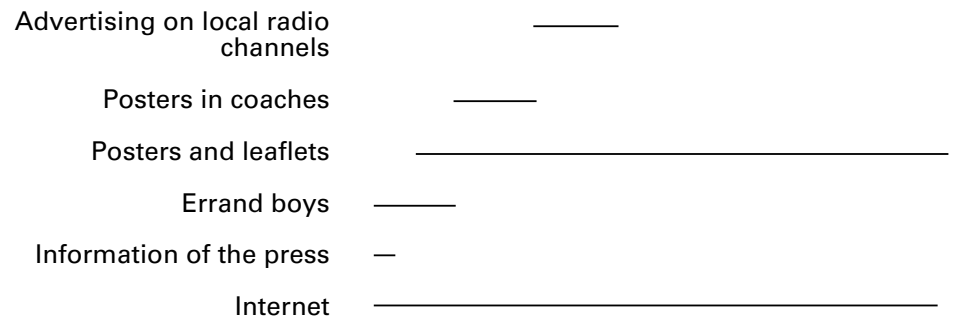

Figure 1 Number of test packages ordered and number of submitted samples related to content of information campaign.

urogenital symptom, as well as the address to where the test result should be sent. A questionnaire was mailed to all participants together with the test result and participants with a positive test result were requested to seek treatment from a doctor.

ANALYSIS OF SAMPLES

All samples were analysed at the department of clinical microbiology, Aarhus University Hospital, using a transcription mediated amplification assay (TMA, Gene-probe) according to the manufacturer's instructions. ${ }^{9}$ Vaginal flush samples were handled as described for urine samples.

OUTCOME MEASURES

The outcome measures were the proportion of tested individuals and number of detected infections.

STATISTICS AND HANDLING OF DATA

The statistical analysis were made in SPSS/PC (ver 8.0). For binomial data (in $2 \times 2$ and $2 \times 3$ tables) the $\chi^{2}$ values were calculated with Yates's correction. Otherwise Fisher's exact test was used.

APPROVAL

The study was approved by the local ethics committee in Aarhus county and the Danish Data protection agency.

\section{Results}

ORDERING OF TEST PACKAGES

During the 14 study weeks, 651 individuals visited the website on the internet (data not shown). Of these 651 website visitors, however, only 60 individuals $(9.2 \%)$ requested a test package. A total of 309 individuals ordered the test package through the answering machine (table 1). Of the individuals requesting the test package through the internet $40 \%(24 / 60)$ were excluded because they lived outside the county and for individuals using the answering machine the figure was $1 \%(3 / 309)$. A total of 196 women $(196 / 205=95.6 \%)$ and 146 men $(146 / 164=89.5 \%)$ received test packages (table 1).

SUBMITTED SAMPLES

Of the 147 women and 86 men who submitted a sample, 28 women and 22 men were excluded because they did not fulfil the age criteria. Thus, 119 of 15000 women $(0.8 \%)$ and 64 of 15000 men $(0.4 \%)$ from the target population were tested.

Prevalence of infection was $8.4 \%(10 / 119)$ and $7.8 \%(5 / 64)$ in females and males, respectively. Four infections in women $(4 / 10=40 \%)$ and three infections in men $(3 / 5=60 \%)$ were asymptomatic.

RELATION BETWEEN CONTENT OF CAMPAIGN AND TEST ACTIVITY

In figure 1 the features of the campaign are related to the number of ordered test packages and number of tests received in the laboratory. A small peak is seen in the first week of the campaign and a second larger peak is coinciding with the advertising on local radio channels. During the last 8 weeks the activity gradually decreased to reach only a few requested test packages at the end of the campaign.

PROFILE OF PARTICIPANTS

The behavioural data obtained from the questionnaires that were sent out to the participants (response rate $157 / 183=85.8 \%$ ) showed that most participants have had six or more lifetime partners and were sexually active during last 6 months (table 2). Most women used oral contraceptives, and $46.3 \%$ of women and $25.7 \%$ of men $\left(\chi^{2}=5.75, p=0.016\right)$ were previously tested for $C$ trachomatis, whereas $26.7 \%$ of women and $8.9 \%$ of men had a positive chlamydia test in the past $\left(\chi^{2}=5.124, \mathrm{p}=0.024\right)$.

\section{Discussion}

This is the first study to address the effectiveness of an information campaign aiming to recruit young adults for $C$ trachomatis testing by home obtained samples. Less than $1 \%$ of men 
Table 2 Description of individuals from the target population (21-23 years) submitting a sample and a questionnaire

\begin{tabular}{|c|c|c|c|c|}
\hline & $\begin{array}{l}\text { Women } \\
n=102\end{array}$ & $95 \% C I$ & $\begin{array}{l}\operatorname{Men}_{n=55}(A S) \\
\end{array}$ & $95 \% C I$ \\
\hline Age at first sexual intercourse & $\mathrm{n}=102$ & & $\mathrm{n}=54$ & \\
\hline 13 to 15 years & $33.3 \%$ & 24.2 to 42.5 & $35.4 \%$ & 21.9 to 49.0 \\
\hline 16 to 18 years & $30.4 \%$ & 21.5 to 39.3 & $48.7 \%$ & 34.6 to 62.9 \\
\hline 19 to 21 years & $36.3 \%$ & 26.9 to 45.6 & $15.8 \%$ & 5.7 to 26.0 \\
\hline Life time partners & $\mathrm{n}=101$ & & $\mathrm{n}=55$ & \\
\hline one partner & $4.0 \%$ & 0.2 to 7.8 & $4.64 \%$ & 0 to 10.1 \\
\hline $2-5$ partners & $30.7 \%$ & 21.7 to 39.7 & $33.1 \%$ & 21.7 to 44.4 \\
\hline 6 or more partners & $65.3 \%$ & 56.1 to 74.6 & $62.3 \%$ & 50.1 to 74.5 \\
\hline Partners during past 6 months ${ }^{\star}$ & $\mathrm{n}=101$ & & $\mathrm{n}=53$ & \\
\hline none & $5.0 \%$ & 0.7 to 9.2 & $1.1 \%$ & 0 to 3.2 \\
\hline one partner & $58.4 \%$ & 48.8 to 68.0 & $48.9 \%$ & 34.3 to 63.6 \\
\hline 2 or more partners & $36.6 \%$ & 27.2 to 46.0 & $50.0 \%$ & 35.4 to 64.6 \\
\hline Current regular relationship & $\mathrm{n}=101$ & & $\mathrm{n}=54$ & \\
\hline yes & $61.4 \%$ & 51.9 to 70.9 & $62.8 \%$ & 48.8 to 76.7 \\
\hline no & $38.6 \%$ & 29.1 to 48.1 & $37.2 \%$ & 23.3 to 51.2 \\
\hline Contraception at last sexual intercourse & $\mathrm{n}=100$ & & $\mathrm{n}=54$ & \\
\hline none & $14.0 \%$ & 7.2 to 20.8 & $17.7 \%$ & 6.6 to 28.9 \\
\hline condom & $20.0 \%$ & 12.2 to 27.8 & $14.3 \%$ & 4.9 to 23.7 \\
\hline oral contraception & $59.0 \%$ & 49.4 to 68.6 & $60.3 \%$ & 46.2 to 74.5 \\
\hline condom and oral contraception & $5.0 \%$ & 0.7 to 9.3 & $2.4 \%$ & 0 to 6.9 \\
\hline other & $2.0 \%$ & 0 to 4.7 & $5.2 \%$ & 0 to 12.2 \\
\hline Previous test for Chlamydia trachomatis $\dagger$ & $\mathrm{n}=101$ & & $\mathrm{n}=54$ & \\
\hline yes & $43.6 \%$ & 33.9 to 53.2 & $25.7 \%$ & 13.2 to 38.2 \\
\hline no & $56.4 \%$ & 46.8 to 66.1 & $74.3 \%$ & 61.8 to 86.8 \\
\hline $\begin{array}{l}\text { Previous positive test for Chlamydia } \\
\text { trachomatis } \ddagger\end{array}$ & $\mathrm{n}=101$ & & $\mathrm{n}=54$ & \\
\hline yes & $26.7 \%$ & 18.1 to 35.4 & $11.1 \%$ & 2.2 to 19.9 \\
\hline no & $73.3 \%$ & 64.6 to 81.9 & $89.0 \%$ & 80.1 to 97.8 \\
\hline
\end{tabular}

(AS) Directly age standardised using age distribution among women as reference.

${ }^{\star}$ Difference between men and women: $\chi^{2}=2.143(\mathrm{df}=2), \mathrm{p}<0.34$.

†Difference between men and women: $\chi^{2}=5.749, \mathrm{p}=0.016$.

$\ddagger$ Difference between men and women: $\chi^{2}=5.124, \mathrm{p}=0.024$.

and women aged 21-23 were tested during the 14 week study period. The prevalence of infection was $8.4 \%$ and $7.8 \%$ for women and men, respectively.

Mass media are often used in health promotion and have been recommended as part of the infection control measure for chlamydia infection. ${ }^{10}$ In a recent review of cervical cancer screening it was concluded that mass media campaigns work best when multiple media are used, when they promote specific screening programmes that eliminate or reduce access barriers, and when they are used in combination with other strategies. ${ }^{11}$ However, even though we used multiple media and gave a unique offer to be tested without seeking a doctor we had a poor response rate. The various components of the campaign had only a short lived effect and continuous promotion seems to be necessary to maintain even a small effect. The effect of the campaign might have been higher if it was performed in a different way, and it may have had effects not measured in this study - for instance, intensified condom use in the population. ${ }^{12}$ However, our study demonstrates that mass media campaigns for chlamydia need careful consideration with regard to cost effectiveness.
The use of mass media to recruit young adults to be tested for Chlamydia trachomatis had only a limited effect, and cannot be recommended as the only measure for recruitment. More effective strategies that reach all individuals in the relevant age group should be searched for.

We grateful acknowledge the superior technical assistance from Mette Jensen, Linda Jensen, Marlis Schlesinger and Gitte Høy, and the excellent work done by Aarhus County.

This work was supported by Aarhus County, the Danish Medical Association Research Fund, the Danish Research Foundation for General Practice, and Nycomed's Research Foundation for members of the Danish College of General Practitioners.

Contributors: BA coordinated the primary study hypothesis and the core ideas, designed the protocol, obtained approval from the ethics committee and data protection agency, coordinated inclusion of patients, made statistical analysis; and coordinated the interpretation of results and wrote the paper; LØ discussed study hypothesis, core ideas, protocol design, discussed interpretation of results, and participated in writing of the paper; JKM discussed study hypothesis and core ideas, led the analysis of samples, discussed interpretation of results and the analysis of samples, discussed interpretation of results and
edited the paper; FO discussed study hypothesis, core ideas, protocol design, interpretation of results, and participated in writing of the paper.

1 Gerbase AL, Rowley TR, Mertens EM. Global epidemiology of sexually transmitted diseases. Lancet 1998; 351 (suppl): $2-4$.

2 Østergaard L, Andersen B, Møller JK, et al. Home sampling versus conventional swab sampling for screening for Chlamydia trachomatis in women: a cluster-randomized 1-year follow-up study. Clin Infect Dis 2000;31:951-7.

3 Østergaard L, Møller JK, Andersen B, et al. Diagnosis of urogenital Chlamydia trachomatis infection in women based on mailed samples obtained at home: multipractice comparative study. BMF 1996;313:1186-9.

4 Rietmeijer CA, Yamaguchi KJ, Ortiz CG, et al. Feasibility Rietmeijer CA, Yamiguchi KJ, Ortiz CG, et al. Feasibility
and yield of screening urine for Chlamydia trachomatis by and yield of screening urine for Chlamydia trachomatis by polymerase chain reaction among high-risk male youth in
field-based and other non clinic settings. A new strategy for sexually transmitted disease control. Sex Transm Dis 1997; 24:429-35.

5 Gaydos CA, Howell MR, Pare B, et al. Chlamydia trachomatis infections in female military recruits. N Engl $\mathcal{F}$ Med 1998;339:739-44.

6 Østergaard L, Andersen B, Olesen F, et al. Efficacy of home sampling for universal screening of Chlamydia trachomatis. $B M \mathcal{F}$ 1998;317:26-7.

7 Marrazzo JM, White CL, Krekeler B, et al. Communitybased urine screening for Chlamydia trachomatis with a ligase chain reaction assay. Ann Intern Med 1997;127:796ligase 803 .

8 Andersen B, Østergaard L, Møller JK, et al. Home sampling versus conventional contact tracing for detecting Chlamydia trachomatis infection in male partners of infected women: randomized study. BMF 1998;316:350-1.

9 Møller JK, Andersen B, Olesen F, et al. The impact of menstrual cycle on the diagnostic performance of LCR, TMA, and PCE for detection of Chlamydia trachomatis in home obtained and mailed vaginal flush and urine samples. Sex Transm Inf 1999;75:228-30.

10 Fouchard JR, Worm AM. [Knowledge, attitude and behavior among patients with Chlamydia trachomatis. Perspecior among patients with Chlamydia trachomatis. P
tives for prevention]. Ugeskr Laeger 1997;159:5085.

11 Marcus AC, Crane LA. A review of cervical cancer screening intervention research: implications for public health programs and future research. Preventive Med 1998;27:1331

12 De Fine Olivarius F, Worm AM, Petersen CS, et al. [Effect of a safe-sex campaign on women attending a clinic of venerology. Sex behavior and prevalence of sexually transmitted diseases in women examined at the Venereaklinik in Copenhagen in 1984 and 1988]. Ugeskr Laeger 1993;155: 3773-6. 